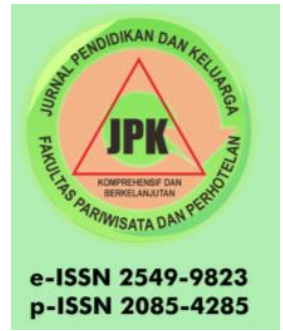

JURNAL PENDIDIKAN DAN KELUARGA

Vol. 11 No. 02, 2019 Page 109-116

DOI: https://doi.org/10.24036/jpk/vol11-iss02

available at http://jpk.ppj.unp.ac.id/index.php/jpk/index

\title{
PENGARUH SERVICESCAPE TERHADAP KEPUASAN TAMU DI FUNCTION ROOM HOTEL THE AXANA PADANG
}

\author{
Jefilo Andas Pratama1, Pasaribu ${ }^{2}$ \\ 1,2 Program studi Manajemen Perhotelan, Jurusan Pariwisata, Fakultas Pariwisata dan \\ Perhotelan, Universitas Negeri Padang. \\ Email: jefilo_andaspratama@yahoo.com
}

Submitted: 2019-07-26

Published: 2019-12-31

DOI: https://doi.org/10.24036/ipk/vol11-iss02/625

URL:http://jpk.ppj.unp.ac.id/index.php/ipk/article/view/625

Accepted: 2019-11-03

\section{Abstract}

This research originated from the results of PLI 2 along with pre-research results for guests using the function room at the Axana Hotel in Padang. This study aims to determine the effect of servicescape on guest satisfaction at the Hotel Axana Padang function room. This type of research is classified into quantitative research with causative associative methods. The research population was all guests using the function room with a total of 3,968 people, with a sample of 98 using purposive sampling technique. Data collection is done using a questionnaire or questionnaire with a Likert scale that has been tested for validity and reliability. Data analysis using simple linear regression and coefficient of determination with the help of SPSS version 16.00. The results showed that: servicescape with a very good category had a percentage of $89.80 \%$ and guest satisfaction with a very good category had a percentage of $71.43 \%$, and the influence of servicescape variables on guest satisfaction was $39 \%$ while $61 \%$ was determined by other factors.

Keywords: Servicescape, Guest Satisfaction, Function Room

\begin{abstract}
Abstrak
Penelitian ini berawal dari hasil PLI 2 beserta hasil pra penelitian terhadap tamu yang menggunakan function room di Hotel Axana Padang. Penelitian ini bertujuan untuk mengetahui pengaruh servicescape terhadap kepuasan tamu di function room Hotel The Axana Padang. Jenis penelitian digolongkan kepada penelitian kuantitatif dengan metode asosiatif kausal. Populasi penelitian yaitu seluruh tamu yang menggunakan function room dengan jumlah 3.968 orang, dengan jumlah sampel 98 menggunakan teknik purposive sampling. Pengumpulan data dilakukan menggunakan kuesioner atau angket dengan skala likert yang telah teruji validitas dan reliabilitasnya. Analisis data menggunakan regresi linear sederhana serta nilai koefisien determinasi dengan bantuan program SPSS versi 16.00. Hasil penelitian menunjukkan bahwa: servicescape dengan kategori sangat baik memiliki persentase $89,80 \%$ dan kepuasan tamu dengan kategori sangat baik memiliki persentase $71,43 \%$, serta pengaruh variabel servicescape terhadap kepuasan tamu sebesar 39\% sedangkan $61 \%$ ditentukan oleh faktor lain.
\end{abstract}

\section{Kata kunci: Servicescape, Kepuasan Tamu, Function Room}

his is an open access article distributed under the Creative Commons 4.0 Attribution License, which permits unrestricted use, distribution, and reproduction in any medium, provided the original work is properly cited. $\subseteq 2017$ by author and Universitas Negeri Padang. 


\section{Pendahuluan}

Pariwisata memiliki dampak bagi kehidupan manusia terutama dalam perkembangan teknologi dan industri. Dampak dari kondisi ini menyebabkan munculnya persaingan antar industri, disini peran pemerintah hanya dibutuhkan untuk memberi ide bagaimana cara mengembangkan serta memajukan industri yang ada terutama dibidang industri pariwisata dan perhotelan. Menurut Undang - Undang No 10 Tahun 2009 Tentang Kepariwisataan, "Pariwisata yaitu suatu kegiatan wisata yang didukung oleh fasilitas serta layanan yang disediakan oleh masyarakat setempat, sesama wisatawan, pemerintah daerah serta pengusaha".

Akomodasi hotel merupakan salah satu jasa yang sangat dibutuhkan oleh para wisatawan. Berdasarkan pendapat Permenparekraf (2013), "Usaha hotel adalah usaha penyediaan akomodasi berupa kamar-kamar di dalam suatu bangunan, yang dapat dilengkapi dengan jasa pelayanan makan dan minum, kegiatan hiburan atau fasilitas lainnya secara harian dengan tujuan memperoleh keuntungan". Selain menginap tamu yang datang ke hotel juga mengadakan event, tamu event itu juga mengharapkan layanan event yang baik. Function room merupakan suatu ruangan yang biasanya digunakan untuk menyelenggarakan rapat, bonus perjalanan, pertemuan, pameran, perjamuan pada suatu periode dengan tujuan berbeda. Dalam sebuah function room diperlukan adanya fasilitas yang baik sebagai penunjang untuk kelancaran event yang dilakukan oleh tamu.

Hotel Axana Padang merupakan hotel yang berbintang empat (****) dan cukup berkembang yang berada di kota Padang. Hotel ini terletak di Jl. Bundo Kanduang No. 14-16, Kp.Pd, Padang Barat, Kota Padang, Sumatera Barat. Lokasi Hotel sangat strategis di pusat kota padang, hanya 5 menit berkendaraan menuju pasar raya dan plaza andalas, dan hanya 10 menit berkendaraaan menuju pantai padang. Hotel ini memiliki 136 kamar yang terdiri dari 43 Superior Room, 77 Deluxe Room, 4 Family Room, 3 Junior Suite Room, dan 9 Executive Room. Hotel The Axana ini memiliki 13 meeting room yang sering digunakan oleh instansi pemerintah atau swasta. Dalam menjalankan operasionalnya, hotel the axana ini mempunyai beberapa departemen yang saling berkaitan diantaranya: Front Office Department, Sales \& Marketing Department, Housekeeping Department, Accounting Department, HRD \& Security Department, Food and Beverage Department, Engginering Department.

Produk, pelayanan dan jasa merupakan hal yang dapat ditawarkan dengan tujuan untuk memberikan kepuasan kepada tamu. Menurut Kotler dan Keller dalam Wardi (2016: 141), "Kepuasan pelanggan adalah perasaan senang atau kecewa pelanggan setelah membandingkan kinerja (hasil) yang dia rasakan dibandingkan dengan harapannya". Indikator dari kepuasan tamu adalah sebagai berikut: tercapainya harapan tamu atau tujuan tamu datang ke hotel, terpenuhinya kebutuhan tamu, tercapainya keinginan tamu, keinginan tamu untuk memakai produk atau jasa itu kembali, Keinginan tamu untuk merekomendasikan produk dan jasa hotel kepada orang lain.

Menurut Irawan dalam Ramadani (2016: 3), "Faktor-faktor yang mempengaruhi kepuasan tamu adalah kualitas pelayanan dan jasa, kualitas produk, harga, emosional faktor, biaya dan kemudahan". Selain produk, fasilitas serta jasa servicescape baik yang dijadikan sebagai penentu kepuasan tamu yang menggunakan function room. Menurut Yazid dalam Masloman, Lumanauw dan Trang (2014), menjelaskan bahwa "Servicescape merupakan lingkungan yang diciptakan, buatan manusia, lingkungan fisik jasa dan bentuk komunikasi berwujud (tangible) lainnya". Menurut Lovelock, Wirtz dan Mussry (2010: 12), indikator servicescape yaitu : kondisi sekitar, spasial layout dan fungsional, tanda atau simbol dan artefak. 
Pada tabel 1 berikut ini dapat di lihat jumlah keseluruhan tamu yang menggunakan function room Hotel The Axana Padang pada bulan Juli - Desember 2018.

Table 1 Jumlah tamu yang menggunakan function room di Hotel The Axana Padang pada bulan Juli-Desember 2018

\begin{tabular}{lll}
\hline No & Bulan & Jumlah \\
\hline 1 & Juli & 5.217 orang \\
\hline 2 & Agustus & 4.032 orang \\
\hline 3 & September & 4.194 orang \\
\hline 4 & Oktober & 1.491 orang \\
\hline 5 & November & 4.657 orang \\
\hline 6 & Desember & 4.216 orang \\
\hline & Jumlah & 23.807 orang \\
\hline
\end{tabular}

Sumber : Data Sekunder, 2019

Berdasarkan hasil pengamatan penulis selama melakukan PLI 2 dan observasi beserta wawancara penulis di lapangan pada waktu pra penelitian tanggal 1 Februari - 11 Februari 2019 kepada 10 orang tamu yang sedang mengadakan meeting di Hotel The Axana Padang. Dari hasil wawancara penulis kepada 10 orang tamu tersebut, tujuh orang tamu tidak puas dengan fasilitas servicescape function room. Adapun keluhankeluhan dari tamu tersebut adalah sebagai berikut: 1) sales dan marketing menjanjikan adanya fasilitas berupa sofa bulat yang bisa diputar tetapi kenyataannya sofa bulat tersebut tidak ada, 2) karyawan sering tidak memberikan apa yang diminta tolong oleh tamu, 3) tamu kesulitan akses jalan untuk menuju ke tempat meeting dan terpaksa tamu harus lewat tangga darurat bila ada salah satu lift yang rusak, 4) suara bising yang terdengar dari luar ruangan yang dapat mengganggu, 5) desain interior function room sudah banyak yang rusak dan karpet function room yang sudah banyak terdapat spot atau kotor, 6) kurangnya kebersihan dari function room, 7) pencahayaan pada function room kurang terang, 8) fasilitas dari ruang meeting kurang memadai, 9) tamu merasa kesulitan untuk keluar dan masuk dari tempat duduk mereka karena space antara meja terlalu kecil, 10) tamu sering bingung untuk mencari tempat ruang meeting karena tanda petunjuk untuk function room kurang jelas.

Urgensi penelitian ini adalah agar pihak hotel dapat mengevaluasi seberapa pentingnya servicescape yang selama ini sudah ada di seluruh function room yang ada di Hotel The Axana Padang. Hal ini bertujuan agar tidak terjadi lagi penurunan jumlah tamu yang mengadakan meeting di Hotel The Axana yang disebabkan oleh ketidakpuasan tamu dan penulis juga ingin melihat penilaian dari tamu terhadap servicescape function room yang disediakan oleh pihak hotel. Penelitian ini bertujuan untuk menganalisis tentang pengaruh servicescape terhadap kepuasan tamu di function room Hotel The Axana Padang .

\section{Metode}

Jenis penelitian ini digolongkan kepada deskriptif kuantitatif dengan metode asosiatif kausal. Populasi dalam penelitian ini yaitu seluruh tamu government dan tamu corporate yang pernah serta sedang menggunakan jasa function room di Hotel The Axana Padang berjumlah 3.968 orang dengan teknik pengambilan sampel menggunakan purposive sampling dengan jumlah 98 orang. Data dalam penelitian ini menggunakan data primer yang diperoleh dari menyebarkan angket kepada responden, yaitu berupa informasi dari tamu tentang servicescape dan kepuasan tamu yang telah di uji validitas serta reliabilitasnya. Data servicescape dengan kepuasan tamu di uji dengan uji regresi 
linear sederhana dengan rumus: $\mathrm{Y}=\mathrm{a}+\mathrm{bx}$ sedangkan untuk menyatakan besar kecilnya pengaruh variabel $\mathrm{X}$ terhadap $\mathrm{Y}$ menggunakan rumus koefisien determinasi yaitu: $\mathrm{Kp}=\mathrm{r} 2 \times 100$ dengan bantuan program SPSS versi 16.99 .

\section{Hasil Penelitian Dan Pembahasan}

\section{Deskripsi Data Variabel Servicescape $(X)$}

Data servicescape diperoleh dari hasil menyebarkan kuesioner yang terdiri dari 12 butir pernyataan yang disebarkan kepada 98 orang yang menggunakan function room di Hotel The Axana Padang yang telah di uji validitas dan reliabilitasnya. Berdasarkan tabel 2 dibawah ini dapat dilihat hasil distribusi frekuensi variabel $\mathrm{X}$.

Table 2 Distribusi Frekuensi Variabel X (Servicescape) N=98

\begin{tabular}{llcc}
\hline Kategori & Rentang Skor & F (Orang) & Persentase (\%) \\
\hline Sangat Baik & $\geq 48$ & 88 & 89,80 \\
\hline Baik & $40-<48$ & 10 & 10,20 \\
\hline Cukup & $32-<40$ & 0 & 0 \\
\hline Buruk & $24-<32$ & 0 & 0 \\
\hline Sangat Buruk & $<24$ & 0 & 0 \\
\hline Total & & 98 & 100 \\
\hline
\end{tabular}

Sumber: Data Primer, 2019 (Diolah)

Berdasarkan perhitungan statistik variabel servicescape terlihat persentase tertinggi sebesar $89,80 \%$ dengan rentang skor $\geq 48$ memiliki kategori sangat baik.

\section{Data Variabel X (Kepuasan Tamu)}

Data kepuasan tamu diperoleh dari menyebarkan kuesioner yang terdiri dari 15 pernyataan yang diberikan kepada 98 responden yang menggunakan function room di hotel The Axana Padang yang telah di uji validitas serta reliabilitasnya. Setelah diperoleh perhitungan statistik variabel kepuasan tamu, dapat diklasifikasikan sebagai berikut:

Table 3 Distribusi Frekuensi variabel Kepuasan Tamu di Function Room Hotel The Axana Padang $\mathrm{N}=98$

\begin{tabular}{lccc}
\hline \multicolumn{1}{c}{ Kategori } & Rentang Skor & F (Orang) & Persentase (\%) \\
\hline Sangat Baik & $\geq 60$ & 70 & 71,43 \\
\hline Baik & $50-<60$ & 26 & 26,53 \\
\hline Cukup & $40-<50$ & 2 & 2,04 \\
\hline Buruk & $30-<40$ & 0 & 0 \\
\hline Sangat Buruk & $<30$ & 0 & 0 \\
\hline Total & & 98 & 100 \\
\hline
\end{tabular}

Sumber: Data Primer, 2019 (Diolah)

Hasil perhitungan statistik variabel kepuasan tamu, diperoleh skor tertinggi $71,43 \%$ dengan rentang skor $\geq 60$, memiliki kategori sangat baik.

\section{Persyaratan Analisis Uji Normalitas}

Table 4 Hasil Uji Normalitas Servicescape dengan kepuasan tamu

(i) This is an open access article distributed under the Creative Commons 4.0 Attribution License, which permits unrestricted use, distribution, and reproduction in any medium, provided the original work is properly cited. (C2017 by author and Universitas Negeri Padang. 


\begin{tabular}{|c|c|c|c|}
\hline \multicolumn{4}{|c|}{ One-Sample Kolmogorov-Smirnov Test } \\
\hline & & Servicescape & Kepuasan_Tamu \\
\hline $\mathrm{N}$ & & 98 & 98 \\
\hline \multirow[t]{2}{*}{ Normal Parameters $^{\mathrm{a}}$} & Mean & 51.83 & 62.21 \\
\hline & Std. Deviation & 3.358 & 5.665 \\
\hline \multirow{3}{*}{$\begin{array}{l}\text { Most } \\
\text { Differences }\end{array}$} & Absolute & .107 & .115 \\
\hline & Positive & .098 & .077 \\
\hline & Negative & -.107 & -.115 \\
\hline \multicolumn{2}{|c|}{ Kolmogorov-Smirnov Z } & 1.058 & 1.142 \\
\hline \multicolumn{2}{|c|}{ Asymp. Sig. (2-tailed) } & .213 & .147 \\
\hline
\end{tabular}

Sumber: Data Primer, 2019 (Diolah)

Dapat dilihat nilai Asymp. Sig servicescape yaitu 213 serta kepuasan tamu di function room 147. Nilai signifikansi $>0,05$, sehingga dapat disimpulkan bahwa kedua data terdistribusi normal.

\section{Uji Homogenitas}

Table 5 Hasil Uji Homogenitas Variabel Servicescape dengan Kepuasan Tamu di Function Room Hotel The Axana Padang

\begin{tabular}{|c|c|c|c|}
\hline \multicolumn{4}{|c|}{ Test of Homogeneity of Variances } \\
\hline \multicolumn{4}{|l|}{ Kepuasan_Tamu } \\
\hline Levene Statistic & df1 & df2 & Sig. \\
\hline .995 & 13 & 82 & .464 \\
\hline
\end{tabular}

Sumber: Data Primer, 2019 (Diolah)

Hasil signifikansi uji homogenitas sebesar $464 \geq 0,05$. Artinya nilai signifikansi data lebih besar dari taraf yang ditentukan, dapat dikatakan bahwa data bersifat homogeny serta berasal dari populasi yang sama. 
Uji Linearitas

Table 6 Data Hasil Uji Linearitas Servicescape dengan Kepuasan Tamu pada Function Room

\begin{tabular}{|c|c|c|c|c|c|c|c|}
\hline \multicolumn{8}{|c|}{ ANOVA Table } \\
\hline & & & $\begin{array}{l}\text { Sum of } \\
\text { Squares }\end{array}$ & $\mathrm{df}$ & $\begin{array}{l}\text { Mean } \\
\text { Square }\end{array}$ & $\mathrm{F}$ & Sig. \\
\hline \multirow{5}{*}{$\begin{array}{l}\text { Kepuasan_ } \\
\text { Tamu* } \\
\text { Servicescap } \\
e\end{array}$} & \multirow{3}{*}{$\begin{array}{l}\text { Between } \\
\text { Groups }\end{array}$} & (Combined) & 1657.463 & 15 & 11.498 & 6.227 & .000 \\
\hline & & Linearity & 1237.661 & 1 & 1237.661 & 69.750 & .000 \\
\hline & & $\begin{array}{l}\text { Deviation } \\
\text { Linearity }\end{array}$ & from $_{419.801}$ & 14 & 29.986 & 1.690 & .074 \\
\hline & \multicolumn{2}{|c|}{ Within Groups } & 1455.037 & 82 & 17.744 & & \\
\hline & \multicolumn{2}{|c|}{ Total } & 3112.500 & 97 & & & \\
\hline
\end{tabular}

Sumber: Data Primer, 2019 (Diolah)

Nilai signifikansi uji linearitas sebesar 0,074 dengan taraf signifikansi > 0,05. Sehingga dapat disimpulkan bahwa terdapat pengaruh yang linear pada kedua variabel tersebut.

\section{Pengujian Hipotesis}

Table 7 R Square variabel servicescape terhadap kepuasan tamu

\begin{tabular}{|c|c|c|c|c|c|}
\hline \multicolumn{6}{|c|}{ Model Summary ${ }^{\mathrm{b}}$} \\
\hline \multirow[b]{2}{*}{ Model } & \multicolumn{2}{|c|}{ Change Statistics } & \multirow[b]{2}{*}{ df1 } & \multirow[b]{2}{*}{ df2 } & \multirow[b]{2}{*}{ Sig. F Change } \\
\hline & R Square Change & F Change & & & \\
\hline 1 & $.398^{\mathrm{a}}$ & 63.374 & 1 & 96 & .000 \\
\hline \multicolumn{6}{|c|}{ a. Predictors: (Constant), Servicescape } \\
\hline \multicolumn{6}{|c|}{ b. Dependent Variable: Kepuasan_Tamu } \\
\hline
\end{tabular}

Berdasarkan tabel di atas, diperoleh nilai $R$ Square sebesar 0,398, dapat dikatakan bahwa pengaruh servicecsape terhadap kepuasan tamu yaitu 39\% sementara itu $61 \%$ dipengaruhi oleh faktor lain seperti: harga, kualitas pelayanan, emosional faktor, biaya dan kemudahan.

\section{Pembahasan}

\section{Servicescape}

Diperoleh sebanyak 88 orang sampel menunjukkan kategori sangat baik, dengan persentase $89,80 \%$ berada pada rentang skor $\geq 48$. Servicescape dapat dilihat dari 3 indikator yaitu: kondisi sekitar (ambient conditions), spasial layout dan fungsional (spatial layout and functional), tanda, simbol, dan artefak (signs, Symbols, and artifacts). Sehingga dapat disimpulkan bahwa servicescape di Hotel The Axana Padang memiliki kategori sangat baik. Sesuai dengan pendapat Lovelock dalam Lumentut dan Palandeng (2014), "Servicescape adalah segala sesuatu yang secara fisik hadir disekitar konsumen selama pertemuan transaksi layanan jasa yang dapat mempengaruhi persepsi pelanggan, baik secara internal maupun eksternal“.

his is an open access article distributed under the Creative Commons 4.0 Attribution License, which permits unrestricted use, distribution, and reproduction in any medium, provided the original work is properly cited. (C2017 by author and Universitas Negeri Padang. 


\section{Kepuasan Tamu}

Berdasarkan penelitian yang telah dilkukan, dapat diperoleh bahwa dari 98 orang sampel untuk variabel kepuasan tamu, terdapt sebanyak 70 orang sampel menunjukkan kategori sangat baik pada persentase $71.43 \%$. Hasil dari pengkategorian persentase di atas, dapat disimpulkan bahwa kepuasan tamu yang pernah dan sedang menggunakan function room di yang didapat dari lima indikator menunujukkan kategori sangat baik. Menurut Tjiptono (2014: 142), "Kepuasan adalah perasaan senang atau kecewa seseorang yang muncul setelah membandingkan kinerja (hasil) jasa yang dipikirkan terhadap kinerja (hasil) yang diharapkan".

Pengaruh Servicescape Terhadap Kepuasan Tamu di Function Room Hotel The Axana Padang. Pengujian hipotesis yang dipakai untuk mencari pengaruh Servicescape tehadap Kepuasan Tamu di Function Room Hotel The Axana Padang dengan menggunakan analisis dengan bantuan SPSS 16.00. Berdasarkan hasil penelitian, ditemukan hasil bahwa nilai konstanta sebesar 7.091 memiliki taraf signifikansi. 0,000 dan diperoleh nilai t sebesar 1,022 dengan taraf, disimpulkan bahwa kedua variabel mempunyai pengaruh yang signifikan, kemudian diperoleh nilai koefisien regresi sebesar 1,064 dengan nilai sig. 0,000 $<0,05$, Artinya setiap peningkatan sebesar 1 satuan servicescape akan meningkatkan 1,064 satuan kepuasan tamu. Selanjutnya diperoleh nilai $R$ Square sebesar 0,398, artinya pengaruh variabel servicescape terhadap variabel kepuasan tamu adalah sebesar 39\% sedangkan 61\% dipengaruhi oleh faktor lain seperti: harga, kualitas pelayanan, faktor emosi, biaya dan kemudahan, sehingga $\mathrm{H}_{a}$ diterima.

Menurut Lovelock dalam Lumentut dan Palandeng (2014), "Servicescape adalah segala sesuatu yang secara fisik hadir disekitar konsumen selama pertemuan transaksi layanan jasa yang dapat mempengaruhi persepsi pelanggan, baik secara internal maupun eksternal“".

Bila servicescape dari function room sesuai dengan yang diharapkan oleh tamu, maka tamu yang pernah dan sedang menggunakan function room akan memberi penilaian yang baik terhadap servicescape function room tersebut. Jika servicescape disediakan melebihi yang diharapkan oleh tamu, maka servicescape tersebut dipersepsiakan ideal. Sebaliknya, jika servicescape yang disediakan buruk dibandingkan dengan yang diharapkan oleh tamu, maka servicescape tersebut dipersepsikan buruk. Oleh sebab itu baik atau buruknya penilaian dari tamu terhadap servicescape yang disediakan tersebut tergantung kepada penyedia jasa dalam memenuhi harapan tamu.

Simpulan

servicescape di function room secara keseluruhan tergolong sangat baik dengan persentase sebesar 89,80\%, kemudian kepuasan tamu di function room Hotel The Axana Padang secara keseluruhan di kategorikan sangat baik dengan persentase sebesar $71,43 \%$. Selanjutnya diperoleh pengaruh yang signifikan antara servicescape terhadap kepuasan tamu berdasarkan hasil uji hipotesis regresi linear sederhana diperoleh nilai konstanta sebesar 7,091 dengan taraf signifikansi 0,000 $<0,05$, kemudian diperoleh nilai koefisien regresi sebesar 1,064 dengan taraf sig. 0,000<0,05, artinya setiap peningkatan sebesar 1 satuan servicescape akan meningkatkan 1,064 satuan kepuasan tamu di function room Hotel The Axana Padang dan diperoleh nilai $R$ Square sebesar 0,398, dapat diartikan bahwa pengaruh variabel servicescape dengan variabel kepuasan tamu di function room Hotel The Axana Padang sebesar 39\%, sedangkan 61\% dipengaruhi oleh faktor lain seperti: faktor emosi, biaya atau kemudahan, harga kualitas pelayanan.

\section{Saran}

\section{Bagi Pihak Hotel The Axana Padang}

Agar pihak hotel dapat menjaga dan melengkapi simbol urgensi seperti: emergency exit dan no smoking signs untuk function room, mengontrol suhu udara di 
function room, meningkatkan kerapian penataan layout untuk function room, menjaga dan merawat dekorasi di dalam fuction room tersebut.

Walaupun penilaian tamu di function room sangat puas terhadap servicescape, tetapi berdasarkan sub indikator harga yang ditawarkan sesuai dengan perjanjian atau kontrak, terpenuhinya harapan pelanggan atau tamu, loyal terhadap produk/jasa, keinginan untuk mempromosikan kepada orang lain, penilaian tamu kurang puas, seharusnya pihak hotel memberikan harga sesuai dengan perjanjian atau kontrak, meningkatkan pelayanan terutama kepada tamu yang menggunakan function room, memberikan apresiasi kepada tamu yang telah menggunakan function room agar tamu merasa dihargai dan puas serta loyal terhadap produk/jasa dan tamu bersedia merekomendasikan produk/jasa kepada orang lain.

\section{Bagi Jurusan Pariwisata Universitas Negeri Padang}

Diharapkan jurusan pariwisata untuk dapat menambah dan melengkapi buku referensi di perpustakaan jurusan yang berkaitan dengan pemasaran jasa, sehingga dapat mempermudah mahasiswa dalam penyusunan skripsi maupun karya tulis ilmiah lainnya.

\section{Bagi Peneliti Selanjutnya}

Disarankan kepada orang yang akam meneliti selanjutnya agar dapat memperluas dan mengembangkan teori tentang faktor-faktor yang berhubungan dengan servicescape seperti: design, warna dan bentuk serta faktor yang berhubungan dengan kepuasan tamu seperti: kualitas produk, kualitas pelayanan, harga, faktor emosional, biaya dan kemudahan.

\section{Daftar Pustaka}

Arikunto, S. (2013). Prosedur Penelitian Suatu Pendekatan Praktik. Jakarta: Rineka Cipta.

Lovelock, C.(Eds.). (2010). Pemasaran Jasa (Manusia, Teknologi, Strategi) Perpektif di Indonesia. Jakarta: Erlangga.

Lumentut, F.L., \& Palandeng, I.D. (2014). Fasilitas, Servicescape, dan Kualitas Pelayananan, Pengaruhnya terhadap Kepuasan Konsumen Mcdonald's Manado. Journal EMBA. 2(3), 126-136.

Masloman, M., Lumanauw, B., \& Trang. I. (2014). Kualitas Pelayanan dan Servicescape Pengaruhnya terhadap Kepuasan Konsumen pada Kentucky Fried Chicken Multimart Ranotana Manado. Jurnal EMBA. 2(4), 589-601.

Peraturan Menteri Pariwisata dan Ekonomi Kreatif Republik Indonesia Nomor 53 Tahun 2013 Standar Usaha Hotel. 27 September 2013. Lembaran Berita Negara Republik Indonesia Tahun 2013 Nomor 1186. Jakarta.

Ramadani, B. (2016). Pengaruh Kualitas Pelayanan Waiter/Waitress terhadap Kepuasan Tamu D'café Restaurant Hotel Axana Padang. Skripsi Padang: Fakultas Pariwisata dan Perhotelan UNP.

Sales \& Marketing Department Hotel The Axana Padang 2019.

Tjiptono, F.(2014). Pemasaran Jasa, Prinsip, Penerapan, Penelitian. Yogyakarta: Andi.

Undang-Undang Republik Indonesia Nomor 10 Tahun 2009 Kepariwisataan. 16 Januari 2009.

Lembaran Negara Republik Indonesia tahun 2009 Nomor 11. Jakarta.

Wardi, Y. (2016). Pemasaran Jasa Realitas di Indonesia. Padang: Sukabina Press.

This is an open access article distributed under the Creative Commons 4.0 Attribution License, which permits unrestricted use, distribution, and reproduction in any medium, provided the original work is properly cited. (C2017 by author and Universitas Negeri Padang. 